Blegur, J., Mae, R.M., \& Wasak, R.P. (2018). Konsep Diri Akademik sebagai Solusi Mengendalikan Kecemasan Berkomunikasi Peserta Didik. Indigenous: Jurnal Ilmiah Psikologi, 3(1), 36-44. doi:https://doi.org/10.23917/indigenous.v3i1.5827

\title{
Konsep Diri Akademik sebagai Solusi Mengendalikan Kecemasan Berkomunikasi Peserta Didik
}

\author{
Jusuf Blegur ${ }^{1}$, Ramona M. Mae ${ }^{2}$, M. Rambu P. Wasak ${ }^{3}$ \\ Universitas Kristen Artha Wacana \\ jusufblegur@ukaw.ac.id ${ }^{1}$ ramona@ukaw.ac.id ${ }^{2}$ rambuwasak@ukaw.ac.id ${ }^{3}$
}

\begin{abstract}
Abstraksi. Tujuan penelitian adalah untuk menghubungkan konsep diri akademik dengan kecemasan berkomunikasi peserta didik dalam proses pembelajaran. Partisipan adalah peserta didik kelas $\mathrm{F}$ yang berjumlah 31 orang yang ditetapkan menggunakan teknik total sampling. Data konsep diri akademik dikumpulkan menggunakan Academic Self-Concept Questionnaire dari Woon C. Liu dan Chee K. J. Wang (2005). Sedangkan data kecemasan berkomunikasi dikumpulkan menggunakan Personal Report of Communication Apprehension dari James C. McCroskey (1982). Hasil uji deskriptif membuktikan konsep diri akademik partisipan tergolong tinggi (83,33\%) dan kecemasan berkomunikasi partisipan tergolong cukup (48,39\%). Partisipan dengan konsep diri akademik yang tinggi lebih mudah mengendalikan kecemasan berkomunikasinya dalam proses pembelajaran, termasuk group discussion, meeting, interpersonal, dan public speaking.
\end{abstract}

Kata kunci: konsep diri akademik, kecemasan berkomunikasi

\section{PENDAHULUAN}

Proses pembelajaran perlu membentuk iklim akademik yang aktif dan akuntabel. Salah satu indikator yang menunjukkan kelas belajar aktif dan akuntabel adalah dengan tingginya intensitas komunikasi antar komunitas belajar dalam berbagai pengembangan aktivitas belajar mereka. Pengembangan pembelajaran terjadi ketika pendidik dan peserta didik saling berkomunikasi guna mengatasi persoalanpersoalan pembelajaran dalam berbagai tingkatan (pertemuan, diskusi, maupun presentasi). Sedangkan pengembangan diri adalah upaya akademik melalui presentasi makalah maupun hasil penelitian dalam seminar, konferensi, simposium, dan sebagainya.

Kondisi ini memposisikan pendidik sebagai pemandu dalam memimpin, merancah, dan mendiskusikan belajar serta mendukung peserta didik dalam mengidentifikasi bagaimana mereka belajar serta apa yang mereka pelajari (Hughes, 2007), ini dapat dilakukan dengan diskusi dan presentasi yang antara lain sebagai upaya mendorong penciptaan dan pengembangan iklim belajar yang efektif, aktif, dan partisipatif (Carpenter, 2006; Kraus \& Sears, 2008; Bankowski, 2010; Beyer, 2010; Faraday, Overton, \& Cooper, 2011).

Kecemasan komunikasi merupakan salah satu faktor afektif yang menentukan kegagalan peserta didik dalam performa akademik, ini termasuk akuisisi bahasa (Mustapha, Ismail, Singh, \& Alias, 2010; Kumaran \& Kadhiravan, 2015). Selain itu, kecemasan berkomunikasi dapat terjadi dalam berbagai derajat dan ditandai oleh perasaan emosional, khawatir, takut, dan stres (Cubukcu, 2008) sehingga peserta didik menjadi kurang responsif terhadap masukanmasukan (Krashen dalam Liu, 2007).

Peserta didik lebih menunjukkan kecemasan komunikasi lisan daripada komunikasi tertulis (Yaikhong \& Usaha, 2012) dan kecemasan juga berlanjut sampai saat mereka dievaluasi atau mendengarkan komunikasi negatif atas performanya (Zhiping \& Paramasivam, 2013). Proses evaluasi ini juga memicu peserta didik untuk menghindar secara "terang-terangan" 
saat ingin tampil (baik mengajukan pertanyaan atau melakukan presentasi). Sebagian peserta didik malah menyikapi secara berlebihan dengan menunjukkan keadasan emosi yang "marah" (Neumann, Forster, \& Strack, 2003) saat ditanyai atau bahkan dievaluasi sejawat atau pendidik.

Kecemasan memang dialami setiap peserta didik, namun tingkat kecemasan berkomunikasi peserta didik berbeda antara satu sama lain dalam fungsi perhatiannya. Lebih khusus, mereka berbeda dalam konten, kapasitas, distraktibilas, dan selektivitas perhatian (Eysenck, 2007). Kecemasan berkomunikasi juga sebenarnya disebabkan oleh situasi performa sebelumnya secara otomatis muncul ketika peserta didik mendapatkan umpan balik kritik selama proses pembelajaran (Robinson, Vargas, \& Crawford, 2003; Villar, 2010).

Hasil pengamatan menjelaskan peserta didik sangat pasif dalam menyampaikan dan mempresentasikan hasil studi lapangan kelompok (poster maupun power point), meskipun mereka sudah diberi waktu persiapan selama 1 sampai dengan 6 minggu. Cenderung monoton dalam aksentuasi dan kaku dalam memainkan gestur. Mendikte naskah tanpa pengayaan dan pengembangan materi melalui analisis-analisis yang analitis dan kontekstual. Ini secara langsung mengiritasi kemampuan berpikir kritis dan kreatif peserta didik sekaligus menjadikan kelas belajar yang tidak efektif dan terkesan hanya memenuhi rutinitas.

Ada berbagai solusi yang digunakan untuk mengatasinya kecemasan komunikasi peserta didik, misalnya menggunakan strategi pedagogi (Kelly \& Keaten, 2000), melatih konsep diri akademik dalam proses pembelajaran (Yahaya \& Ramli, 2009), membentuk dukungan sosial (Beehr \& McGrath, 2007), melakukan diskusi kelompok (Mustapha, Ismail, Singh, \& Alias, 2010), serta menciptakan persahabatan, karena teman-teman dapat mereduksi kecemasan evaluasi negatif dan meningkatkan kepercayaan diri peserta didik (Humphries, 2011).

Pada kesempatan ini, peneliti hanya membatasi wilayah penelitian pada konsep diri akademik untuk mencari korelasinya dengan kecemasan berkomunikasi peserta didik dalam kegiatan pembelajaran. Konsep diri akademik sendiri mengacu pada pemahaman dan persepsi peserta didik terhadap diri mereka sendiri yang dikembangkan melalui upaya serta interaksi tertentu untuk prestasi akademik (Wigfield \& Karpathian, 1991; Valentine, DuBois, \& Cooper, 2004). Hipotesis penelitian adalah terdapat hubungan yang negatif dan signifikan antara konsep diri akademik dengan kecemasan berkomunikasi peserta didik.

\section{METODE PENELITIAN}

Metode Penelitian ini didesain untuk mendeskripsikan variabel konsep diri dan kecemasan berkomunikasi peserta didik serta mencari korelasi dari kedua variabel penelitian. Perasaan, pandangan, atau pendapat yang bermuara pada konsep diri akademik dan kecemasan berkomunikasi telah dirangkum dalam kuesioner (ASCQ dan PRCA-24).

Jumlah populasi dapat dijangkau oleh peneliti dalam segi waktu, tenaga, dan anggaran, sehingga peneliti menggunakan penelitian populasi, yang mana seluruh poplulasi peneliti tetapkan sebagai partisipan. Dengan demikian, partisipan yang terlibat dalam penelitian berjumlah 31 orang peserta didik kelas $\mathrm{F}$ Program Studi Pendidikan Jasmani, Kesehatan, dan Rekreasi Universitas Kristen Artha Wacana yaitu 25 laki-laki dan 6 perempuan $(\mathrm{M}=$ 22,0645, SD = 1,69185).

Data konsep diri akademik dikumpulkan dengan Academic Self-Concept Questionnaire (ASCQ) dari Woon C. Liu dan Chee K. J. Wang di tahun 2005. ASCQ dikonstruksi dari 2 sub variabel, mencakup: 1) Keyakinan akademik, yaitu penilaian tentang perasaan dan persepsi peserta didik tentang kompetensi akademiknya dan 2) Upaya akademik, penilaian tentang komitmen peserta didik tentang keterlibatannya pada proses pembelajaran.

Data kecemasan berkomunikasi dikumpulkan dengan Personal Report of Communication Apprehension (PRCA-24) dari James C. McCroskey di tahun 1982. PRCA-24 terdiri dari 24 pernyataan tertutup yang dikemas dalam empat sub variabel, antara lain group discussion, meetings, interpersonal, dan public speaking. Seluruh data penelitian dianalisis secara deskriptif untuk mempresentasikan dan 
menilai konsep diri akademik dan kecemasan berkomunikasi peserta didik. Sedangkan analisis Pearson digunakan untuk mencari hubungan variabel konsep diri akademik dengan variabel kecemasan berkomunikasi sebagai bentuk pengujian hipotesis penelitian.

\section{HASIL DAN PEMBAHASAN}

Hasil Hasil penelitian dan proses analisis serta diskusi dipaparkan bagian per bagian, baik dari konsep diri akademik (keyakinan akademik dan upaya akademik), kecemasan berkomunikasi (group discussion, mettings, interpersonal, dan public speaking), serta diakhiri dengan pengujian korelasi kedua variabel penelitian menggunakan analisis dari Pearson.

Penilaian kedua kelompok variabel dilakukan secara deskriptif, yakni pada lima kategori penilaian (sangat rendah sampai sangat tinggi). Untuk variabel konsep diri akademik, nilai terendah adalah 20, sedang tertinggi adalah 100. Sedangkan untuk variabel kecemasan berkomunikasi dengan nilai terendah adalah 24 dan nilai tertinggi adalah 120. Proporsi penilaian (frekuensi) kedua kelompok variabel penelitian dapat disimak pada gambar 1 .

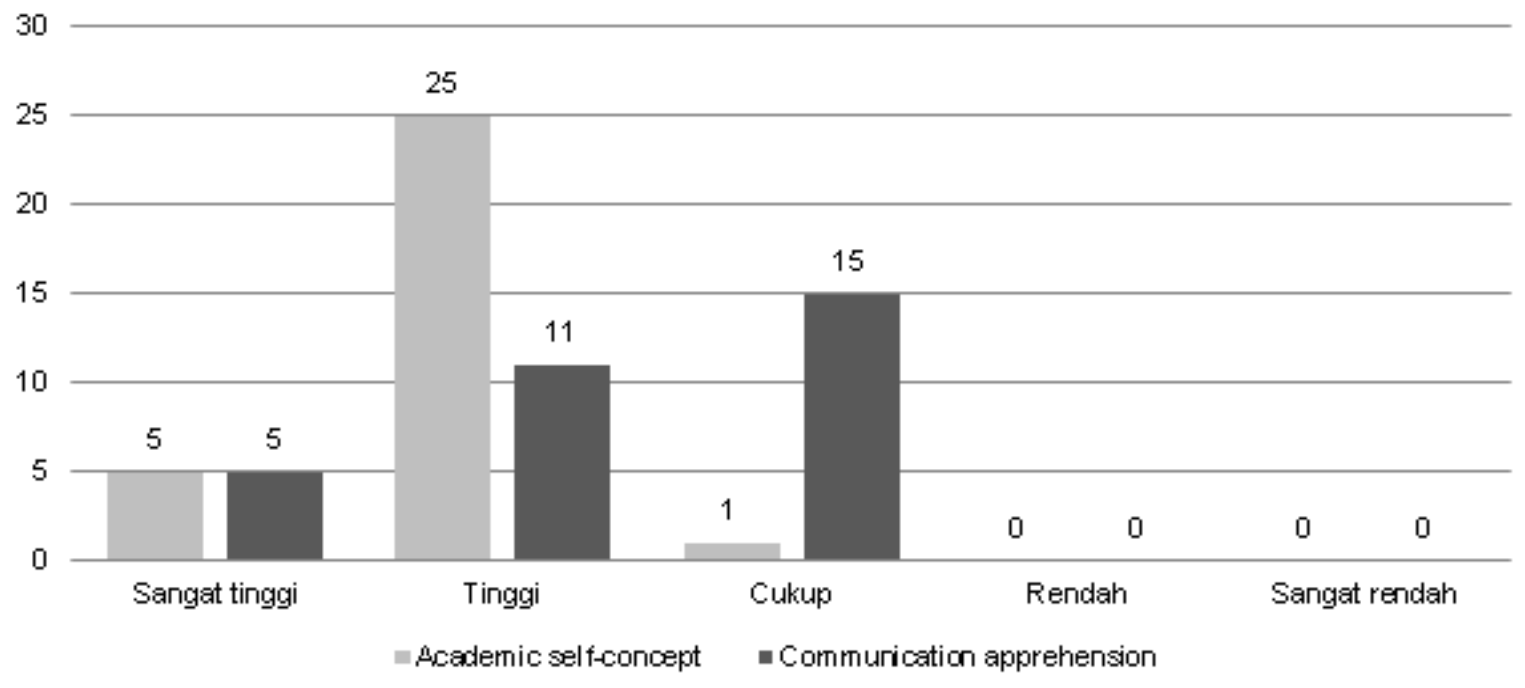

Gambar 1. Penilaian kedua kelompok variabel

Tabel Diagram batang pada gambar 1 telah menunjukkan penilaian secara parsial dari kedua kelompok variabel penelitian. Sebagai variabel bebas yang dipakai untuk memprediksi kecemasan berkomunikasi peserta didik, ternyata konsep diri akademik peserta didik tergolong tinggi $(83,33 \%)$. Data ini sekaligus menjelaskan bahwa peserta didik memiliki keyakinan dan upaya akademik yang baik dan positif dalam melaksanakan proses pembelajaran, meskipun masih dijumpai keyikan dan perilaku yang pesimis tidak membuat mereka ragu atas kemampuan diri mereka.

Sedangkan data kecemasan berkomunikasi pasca difrekuensikan, peserta didik menempati tingkat cukup $(48,39 \%)$. Artinya kecemasan berkomunikasi peserta didik berada dalam kondisi netral, sehingga kecemasan berkomunikasi peserta didik akan memberi dampak yang cukup terhadap arah kualitas diskusi, pertemuan, interpersonal, maupun publik speaking peserta didik selama mengikuti proses pembelajaran di dalam kelas. Dengan demikian peserta didik masih perlu didorong untuk menekan kecemasan berkomunikasinya agar Ia dapat berpartisipasi secara maksimal guna memberi gagasan-gagasan yang lebih produktif untuk kelompok dan kelas belajarnya.

Keyakinan peserta didik atas kemampuan juga termasuk mereka dapat melakukan performa yang lebih baik dari teman-teman lain hampir pada semua mata pelajaran $(48,4 \%)$. Keyakinan ini sebagai hasil dari proses evaluasi diri dalam kegiatan belajar peserta didik. Hampir pada semua pelajaran, tugas-tugas yang dikerjakan, peserta didik mendapat hasil memuaskan 
sehingga adanya pembentukan keyakinan dalam diri tentang kemampuan akademiknya. Saat keyakinan akademik terbentuk dengan baik, peserta didik termotivasi untuk menjaga kualitas belajarnya agar Ia tetap stabil.

Paling penting ialah bagaimana peserta didik membentuk keyakinan akademik didirnya sendiri, agar Ia tidak merasa "buruk" dihadapan pendidik dan sejawatnya. Apalagi dalam hal mempersipkan diri dengan perasaan yakin untuk menyelesaikan tugas membantu mereka untuk menempatkan tugas-tugas belajar sebagian bagian yang tidak perlu dihindari, melainkan diselesaikan secara tuntas. Peserta didik tidak mengelak terhadap beban tugas yang didapatkanya, sehingga mendorongnya untuk berupaya secara baik sebagai pemenuhan atas persepsi keyakinan akademik yang dimiliknya sendiri.

Sebagai peserta didik pendidikan tinggi, tugas yang mereka terima cenderung menantang karena dirancang untuk mendorong tingkat berpikir dan analisis yang tinggi dari mereka. Selain itu, dengan tugas yang menantang, pendidik membiasakan diri untuk tidak hidup dalam "zona hijau" yang cenderung statis dan mengesampingkan upaya-upaya belajar yang solutif. Tidak ada peserta yang tuntas tanpa melakukan upaya, karena pendidik menggunakan standar upaya yang tinggi agar tuntas dalam belajar, seperti menyusun makalah dan melakukan presentasi secara personal.

Peserta didik menunjukkan perilaku belajar yang tidak mudah menyerah ketika menghadapi kesulitan dalam tugas-tugas, seperti mereka melakukan perbaikan makalah dengan mencari rujukan-rujukan (jurnal dan prosiding) yang mutakhir dengan batasan minimal 8 rujukan. Mereka juga awalnya mengalami kesulitas dalam mengutip dan menulis referensi dengan American Psychological Style (APA), namun dapat menyusunnya secara perlahan-lahan. Walaupun dengan dampingan pendidik, semangat pantang menyerah dan kesungguhan dari peserta didik membuat aktivitas belajar lebih berguna dan bermanfaat bagi diri mereka sendiri.

Untuk variabel kecemasan berkomunikasi, konflik dan ketidakharmonisan dalam sebuah pertemuan juga umumnya dipicu tanggapan peserta pertemuan yang kerap "egois dan arogan". Mereka tidak berfokus pada penyelesaian masalah, melainkan pada subyek per subyek yang berbuat kelalaian dalam mengemban tanggung jawab. Sehingga saat memberi tanggapan dalam pertemuan, ekspreasi wajahnya datar, nada suaranya meninggi, serta bahasa tubuhnya sangat "ekspresif". Jika kondisi ini terjadi dalam sebuah pertemuan, maka dipastikan kelompok belajar tidak akan mendapatkan hasil yang positif dari pertemuan tersebut.

Namun demikian dalam pengujian deskriptif ini, peserta didik menunjukkan gelora emosi yang stabil dan positif, mereka ternyata tidakhanya santai dan tenangdalamberpartisipasi pada pertemuan, menyampaikan pendapat pada pertemuan, melainkan mereka juga sangat santai dan tenang ketika menjawab pertanyaan dalam suatu pertemuan. Ini menunjukkan bahwa kecemasan komunikasi belum dominan saat peserta didik mempersepsikan pertemuan sebagai gambaran emosi mereka.

Saat peserta didik cemas berkomunikasi, bagian tubuh mereka bereaksi, seperti Ia berkeringat secara berlebihan, kaku dalam mengekpresikan diri, tidak mampu menatap audiens saat menyajikan materi, serta tangan atau kaki terasa bergetar. Kondisi ini kerap dirasakan peserta didik dengan konsep diri akademik yang buruk, sehingga la membuat perhatian dan konsentrasinya menjadi kacau balau dan bingung ketika saya sedang menyajikan materi diskusinya. Ia bahkan merasa ragu atas setiap aktivitas atau perilaku yang Ia lakukan di dalam kelas.

Sebenarnya kondisi ini bukan terjadi karena intervensi berlebih dari luar, melainkan ketidaksiapan peserta didik yang membuatnya merasa cemas secara berlebih. Selain itu, peserta didik juga lebih dahulu mempersepsikan diri tidak lebih baik dari orang lain sehingga perasaannya menjadi tidak tenang untuk mengaktualisasikan diri dalam kegiatan presentasi, sehingga kecemasan komunikasi dikaitkan secara negatif dengan kesediaan siswa untuk meraih peluang kepemimpinan, penghargaan terhadap dunia multikultural, dan kemampuan beradaptasi terhadap situasi baru (Blume \& Baldwin, 2013). 
Memang tidak semua peserta didik merasakan publik speaking yang buruk, akan tetapi kondisi di atas terjadi pada beberapa peserta didik dengan keyakinan dan upaya akademik yang labil, termasuk berdampak terhadap presentasi mereka begitu gugup sehingga melupakan apa yang harus saya katakan. Peserta didik dengan keyakinan diri tinggi, akan mampu menyaring dan mengendalikan respon eksternal dengan baik. Dimana mereka tidak merasa lebih buruk dari orang lain sehingga apa yang hendak dilakukan tidak terpusat pada satu perspektif penilaian, melainkan mereka memberi sebuah perspektif bahwa Ia juga dapat melakukannya dan bahkan dengan cara-cara yang lain selama tujuannya tercapai.
Kecemasan komunikasi hanyalah persoalan ketidakpercayaan diri (Siska, Sudarjo, \& Purnamaningsih, 2003), lemahnya upaya belajar, buruknya penghargaan diri, serta pengalaman berkomunikasi yang rendah (Muslimin, 2013). Selama variabel-variabel tersebut dapat "kondisikan" dan dibiasakan, maka persoalan publik speaking tidak akan mengganggu kualitas diri peserta didik dalam pembelajaran.

Pasca deskripsi data penelitian guna mengetahui nilai frekuensi dan presentasi variabel konsep diri akademik (X) dan kecemasan berkomunikasi $(\mathrm{Y})$, penelitian dilanjutkan ke proses analisis Pearson dapat dilihat di tabel 1.

Tabel 1. Analisis Pearson

\begin{tabular}{cccc}
\hline & & $\begin{array}{c}\text { Konsep diri } \\
\text { akademik }\end{array}$ & $\begin{array}{c}\text { Kecemasan } \\
\text { berkomunikasi }\end{array}$ \\
\hline $\begin{array}{c}\text { Konsep diri } \\
\text { akademik }\end{array}$ & Pearson correlation & 1 & $0,610^{* *}$ \\
sig. (2-tailed) & $\mathrm{N}$ & 31 & 0,000 \\
Kecemasan & Pearson correlation & $0,610^{* *}$ & 31 \\
berkomunikasi & sig. (2-tailed) & 0,000 & 1 \\
& $\mathrm{~N}$ & 31 & 31 \\
\hline
\end{tabular}

${ }^{* *}$. Correlation is significant at the 0.01 level (2-tailed).

Hasil pengujian membuktikan adanya korelasi negatif yang signifikan antara konsep diri akademik (keyakinan dan upaya) dengan kecemasan berkomunikasi peserta didik $(0,000$ $<0,05)$ dengan nilai $r=0,610$. Kian tingginya konsep diri akademik ternyata mampu menekan rasa kecemasan berkomunikasi peserta dalam proses pembelajaran.

Untuk mengatasi kecemasan berkomunikasi, pendidik dapat mendorong dan menguatkan kapasitas kopsep diri akademik (keyakinan dan upaya) peserta didik (FathiAshtiani, Ejei, Khodapanahi, \& Tarkhorani, 2007; Kaur \& Kumaran, 2016), misalnya dengan cara mempersepsikan diri sebagai pembelajar (Emmanuel, Adom, Josephine, \& Solomon, 2014), memiliki tren positif dalam menyelesaikan tugas belajar, atau bahkan merasa bahwa tugas yang diberikan oleh pendidik tidak sulit. Selain itu, peserta didik perlu diajarkan untuk menikmati proses belajar dengan upaya-upaya kreatif dalam mencari informasiinformasi solutif agar memperbanyak peluang dan mempercepat penyelesaian kesulitan belajar, termasuk kecemasannya dalam berkomunikasi di kelas.

Konsep diri akademik sebagai pemahaman, persepsi, upaya, dan interaksi peserta didik untuk performa akademiknya (Wigfield \& Karpathian, 1991; Valentine, DuBois, \& Cooper, 2004). Saat peserta didik merasa yakin atas kemampuannya, maka Ia cepat terlibat dalam tugas belajar. Peserta didik lebih efisien memecahkan masalah, menunjukkan ketekunan, dan lebih mampu memonitor waktu dalam mengerjakan tugas (Goldberg, 2014). Mereka tidak hanya ingin terlibat, melainkan segera membuktikan bahwa kompetensi akademiknya melampaui kesulitan yang ada (Liu \& Wang, 2005; Arefi \& Naghebzadeh, 2014).

Tugas yang diberikan memang dalam jangkauan pengalaman peserta didik atau bahkan 
tanpa pengalaman pun, mereka berkeyakinan bahwa segala sesuatu ada solusinya, sehingga tidak ada pilihaan menyerah pada tugas. Seperti contohnya peserta didik yang merasa bahwa bertanya, berdiskusi, dan bahkan melakukan presentasi bukanlah sesuatu yang sulit, mengapa demikian? Ya, memang karena proses demikian tidak membuat peserta didik "cacat fisik". Selain itu, kegiatan belajar yang peserta didik anggap sebagai proses melakukan refleksi diri, perbaikan atas performa, serta pengembangan kualitas pembelajaran.

Keyakinan untuk menaklukkan tantangan atau hambatan akan berjalan lancar dengan aksi-aksi nyata sebagai bentuk upaya belajar. Sebab keyakinan adalah kesiapan peserta didik untuk memberikan bukti, namun sebagaimana diketahui kesiapan yang kental dengan tujuan tidak selalu selaras dengan harapan yang peserta didik inginkan. Selama proses mencapai tujuan ada berbagai hambatan yang terjadi di luar kendali peserta didik, misalkan materi yang didapat sangat sulit, atau pertanyaan yang datang sangat kritis (Karatia, 2015), atau bisa jadi soal kondisi fisik yang tidak stabil.

Kejadian-kejadian di luar prediksi inilah yang hanya dapat diatasi peserta didik dengan melakukan upaya-upaya, agar Ia benar-benar siap (baik secara mentalitas maupun fisikal) dengan tingginya komitmen dan ketekunan (Liu \& Wang, 2005; Ommundsen, Haugen, \& Lund, 2007). Berupaya itu tidak mengenal rasa jenuh, karena upaya peseta didik berorientasi pada tujuan. Sehingga apabila peserta didik merasa tujuannya belum tercapai (masih cemas), Ia akan selalu memperbaiki diri dengan latihan dan persiapan (Villar, 2010), meningkatkan motivasi, membentuk kesenangan, kedalaman pengolahan informasi, integrasi pengetahuan, serta menggeneralisasi pengetahuan (Guay \& Vallerand, 1996).

Pembelajaran sebagai adalah pusat komunikasi diantara sesama peserta didik, sehingga aneh jika dalam pembelajar tidak terjadi komunikasi. Saat memberi masukan harus berkomunikasi, saat berdiskusi harus berkomunikasi, dan saat memberi masukan itu pun harus dengan berkomunikasi. Artinya berkomunikasi adalah bagian penting dalam kegiatan pembelajaran sebab pembelajaran tidak akan berhasil tanpa komunikasi.

Peserta didik harus tahu bahwa kecemasan berkomunikasi hanya menghambat eksplorasi diri, menghambat kebermaknaan kelas belajar, serta memperburuk performa akademik peserta didik (Zhiping \& Paramasivam, 2013), dengan marasa khawatir, takut, dan stres (Cubukcu, 2008), kurang responsif dengan masukan yang kritis (Krashen dalam Liu, 2007; Zhiping \& Paramasivam, 2013), serta cenderung emosional dengan merasa perubahan sebagai ancaman (Neumann, Forster, \& Strack, 2003; Blume \& Baldwin, 2013). Selain itu, ketika peserta didik cemas untuk berkomunikasi, ada banyak gagasan menarik yang tidak muncul ke ruang diskusi karena hanya "tersimpan rapih" dalam memori. Bisa jadi gagasan yang tersimpan rapih itulah yang dapat menjadi solusi ampuh untuk mengatasi masalah dan bahkan meningkatkan kualitas belajar dengan nilai orisinalitasnya.

Berkomunikasi dengan santai, tenang, dan bebas adalah hal yang menggembirakan bagi peserta didik dan pendidik. Perasaan mereka begitu "lepas" untuk mengajak orang lain untuk berpendapat maupun berdiskusi, sehingga aktivitas diskusi dalam kelas belajar tidak terjadi karena adanya paksanaan atau tekanan dari pendidik melainkan karena suatu kebutuhan dasar belajar yang diprakarsai oleh peserta didik sendiri. Alhasil kapasitas pendidik dalam kegiatan belajar hanyalah sebagai fasilitator, mediator, konfirmator, dan evaluator.

Tidak hanya tentang penguasan materi dan keterampilan, akan tetapi saat peserta tidak cemas berkomunikasi mereka akan lebih mudah mengenal dan mendalami kepribadian sejawatsejawatnya. Membantu peserta didik dalam mengendalikan emosi dan kehidupan sosialisasi antarprofesional lintas budaya (LaRochelle \& Karpinski, 2016). Sebab bagaimana mungkin mereka dapat saling mengenal dalam keakraban, ketika peserta didik satu sama lain yang memiliki perbedaan enggan berkomunikasi dalam membangun relasi sosialnya?

Pembelajaran yang berkualitas adalah idaman semua pelaku belajar (pendidik dan peserta didik), sehingga setiap aktivitas yang dirancang, selalu mereferensi pada kualitas 
tersebut. Kualitas pembelajaran adalah totalitas peserta didik untuk berpartisipasi dalam kegiatan pembelajaran. Segala kemampuan terbaik disumbangkan untuk menghidupkan kelas dengan intervensi pendidik dalam menciptakan ilmik belajar yang akademistik agar mengawal keyakinan dan upaya belajar peserta didik sambil melakukan pendampingan dan pemberdayaan secara berkelanjutan (Tlonaen \& Blegur, 2017).

Kualitas belajar bukan tentang angka semata, melainkan tentang "makna" proses prosedural dan metaanalisis yang peserta didik dapat setelah mengkahiri kegiatan belajar. Akhirnya konsep diri akademik memediasai peserta didik untuk tidak cemas berkomunikasi dengan keyakinan dan upaya akademik (Kaur \& Kumaran, 2016), memproyeksi prestasi belajar peserta didik (Awad, 2007; Emmanuel, Adom, Josephine, \& Solomon, 2014), serta dipakai sebagai indikator kualitas pembelajaran (Liu, 2010), karena peserta didik menunjukkan arah transformasi yang positif (dari cemas berkomunikasi menjadi tidak cemas berkomunikasi).

\section{SIMPULAN}

Isi Peserta didik merasakan adanya krisis pengalaman belajar, berdasarkan krisis ini peserta didik terdorong untuk belajar lebih giat. Selain itu, peserta didik tidak dimanjakan pendidik dengan nilai "gampang", sehingga tidak ada pilihan lain selain melakukan upaya karena setiap peserta didik pada dasarnya memiliki kemampuan dan potensi diri, hanya mereka malas mengembangkannya karena telah larut hidup dalam "zona nyaman", yang cenderung mengidamkan hasil tanpa melewati proses. Padahal proses itulah hasil belajar peserta didik sesungguhnya dalam kegiatan pembelajaran, kerena mengenalkan mereka tahapan-tahapan dalam melewati kendala dan hambatan, termasuk kecemasannya dalam berkomunikasi.

Pendidik perlu mendukung peserta didik untuk menyelidiki basis-basis yang meyakinkan mereka atas kemampuan mereka miliki, karena setiap peserta didik memiliki kemampuan pada dirisendiri, namun merekabingung menentukan kemampuannya dan apalagi meyakininya. Selepas itu, dampingi dan bimbinglah mereka kepada optimalisasi keyakinan itu dengan upaya-upaya belajar yang aktif seturut dengan preferensi belajarnya agar adanya inisiasi untuk belajar tanpa harus "dikontrol secara ketat" oleh pendidik dalam setiap aktivitasnya. Kecemasan komunikasi ini hanya sebuah cerminan dari rasa tidak yakin peserta didik pada kemampuan dirinya dan diperparah dengan mobilisasi upaya belajar yang rendah membuat peserta didik kian bingung dan cemas dalam membuat keputusan yang solutif.

\section{UCAPAN TERIMAKASIH}

Ucapan terima kasih disampaikan kepada Direktorat Jenderal Pendidikan Tinggi Kementrian Riset, Teknologi, dan Pendidikan Tinggi yang berkenan menjadi sponsor pelaksanaan penelitian pada skim Penelitian Dosen Pemula. Ucapan terima kasih juga disampaikan kepada Ibu June A. Jacob, S.Pd., M.A., selaku Dekan Fakultas Keguruan dan Ilmu Pendidikan, serta Bapak Agustinus J. Nafie, S.Pd., M.Or., selaku Ketua Program Studi Pendidikan Jasmani, Kesehatan, dan Rekreasi yang berkenan memberikan izin dan mendukung seluruh proses penelitian.

\section{DAFTAR PUSTAKA}

Arefi, M., \& Naghebzadeh, M. (2014). The relation between academic self-concept and academic motivation and its effect on academic achievement. Indian Journal of Fundamental and Applied Life Science, 4, 3225-3230.

Awad, G. H. (2007). The role of racial identity, academic self-concept, and Self-esteem in the prediction of academic outcomes for African American Students. Journal of Black Psychology, 33(2), 188-207. doi: 10.1177/0095798407299513.

Bankowski, E. (2010). Developing skills for effective academic presentations in EAP. International 
Journal of Teaching and Learning in Higher Education, 22(2), 187-196.

Beehr, T. A., \& McGrath, J. E. (2007). Social support, occupational stress and anxiety. Journal Anxiety, Stress, \& Coping: An International Journal, 5, 7-19.

Beyer, C. K. (2010). Innovative strategies that work with nondiverse teachers for diverse classrooms. Journal of Research in Innovative Teaching, 3(1), 114-124.

Blume, B. D., \& Baldwin, T. T. (2013). Communication apprehension: A barrier to students' leadership, adaptability, and multicultural appreciation. Academy of Managemen Learning and Education, 12(2), 158-172. http://dx.doi.org/10.5465/amle.2011.0127

Carpenter, J. M. (2006). Effective teaching methods for large classes. Journal of Family \& Consumer Sciences Education, 24(2), 13-23.

Cubukcu, F. (2008). A study on the correlation between self efficacy and foreign language learning anxiety. Journal of Theory and Practice in Education, 4(1), 148-158.

Emmanuel, A. O., Adom, E. A., Josephine, B., \& Solomon, F. K. (2014). Achievement motivation, academic self-concept and academic achievement among high school student. European Journal of Research and Reflection in Educational Sciences, 2(2), 24-37.

Eysenck, W. M. (2007). Anxiety and attention. Journal Anxiety Research, 1(1), 9-15. http://dx.doi. org/10.1080/10615808808248216

Faraday, S., Overton, C., \& Cooper, S. (2011). Effective teaching and learning in vocational education. London: LSN.

Fathi-Ashtiani, A., Ejei, J., Khodapanahi, M. K., \& Tarkhorani, H. (2007). Relationship between self-concept, self-esteem, anxiety, depression and academic achievement. Journal of Applied Sciences, 7(7), 995-1000.

Goldberg, Y. T. (2014). The effect of ability grouping for talmund the academic self-concept of jewish orthodox middle school students. Dissertation Doctoral, School Psychology, Walden University.

Guay, F., \& Vallerand, R. J. (1996). Social context, student's motivation, and academic achievement: Toward a process model. Social Psychology of Education, 1(3), 211-233.

Hughes, P. (2007). Learning about learning or learning to learn (L2L)," in Anne Campbell \& Lin Norton (ed), Learning, teaching, and assessing in higher education: Developing reflective practice (pp. 9-20). Southhernhay East: Learning Matters, Ltd.

Humphries, R. (2011). Language anxiety in international students: How can it be overcome?," Griffitg Working Paper in Pragmatics and Intercultural Communication, 4(1), 65-77.

Karatia. (2015). Study of emotional intelligence among adolescents in relation to self confidence. International Educational E-Journal, 4(1), 88-95.

Kaur, G., \& Kumaran, S. J. (2016). Test anxiety and academic self-concept of students. The international Journal of Indian Psychology, 3(4), 90-98.

Kelly, L., \& Keaten, J. A. (2010). Treating communication anxiety: Implications of the communibiological paradigm. Communication Education, 49(1), 45-57.

Kraus, S., \& Sears, S. (2008). Teaching for the millennial generation: Student and teacher perceptions of communicaty building and individual pedagogical techniques. The Journal of Effective Teaching, 8(2), 32-39.

Kumaran, K., \& Kadhiravan, D. (2015). Personality and test anxiety of school students. International Journal of Education and Psychological Research, 4(2), 9-13.

LaRochelle, J. M., \& Karpinski, A. C. (2016). Racial differences in communication apprehension and interprofessional socialization in fourth-year doctor of pharmacy students. American Journal of 
Pharmaceutical Education, 80(1), 1-9. doi: 10.5688/ajpe8018

Liu, H. J. (2010). The relation of academic self-concept to motivation among university EFL students. Feng Chia Journal of Humanities and Social Sciences, 20, 207-225.

Liu, M. (2007). Anxiety in oral English classrooms: A case study in China. Indonesian Journal of English Teaching, 3(1), 119-137.

Liu, W. C., \& Wang, C. K. J. (2005). Academic self-concept: A cross-sectional study of grade and gender differences in a Singapore secondary school. Asia Pacific Education Review, 6(1), 20-27.

McCroskey, J. C. (1982). An introduction theorical communication. Englewood Cliffs, NJ: Prentice-Hall.

Muslimin, K. (2013). Faktor-faktor yang mempengaruhi kecemasan berkomunikasi di depan umum (kasus mahasiswa fakultas dakwah INISNU Jepara). Jurnal Interaksi, 2(2), 42-52. https://doi. org/10.14710/interaksi,2,2,

Mustapha, W. Z. W., Ismail, N., Singh, D. S. R., \& Alias, S. E. (2010). ESL students communication apprehension and their choice of communicative activities. AJTLHE, 2(1), 22-29.

Neuman, R., Forster, J., \& Strack, F. (2003). Motor compatibility: The bidirectional link between behavior and evaluation. in Jochen Musch \& Karl C. Klauer (ed), The psychology of evaluation: Affective processes in cognition and emotion (pp. 371-392). New Jersey, Lonson: Lawrence Erlbaum Associates, Publisher, 2003, pp. 371-392.

Ommundsen, Y., Haugen, R., \& Lund, T. (2007). Academic self-concept, implicit theories of ability, and self-regulation strategies Scandinavian Journal of Education Research, 49(5), 461-474, 2007, doi.org/10.1080/00313830500267838.

Robinson, M. D., Vargas, P. T., \& Crawford, E. G. (2003). Putting process into personality, appraisal, and emotion: Evaluative processing as a missing link, in Jochen Musch \& Karl C. Klauer (ed), The psychology of evaluation: Affective processes in cognition and emotion (pp. 371-392). New Jersey, London: Lawrence Erlbaum Associates, Publisher.

Siska, Sudarjo, \& Purnamaningsih, E. H. (2003). Kepercayaan diri dan kecemasan komunikasi interpersonal pada mahasiswa. Jurnal Psikologi, 30(2), 67-71. 10.22146/jpsi.7025

Tlonaen, Z. A., \& Blegur, J. (2017). Konsep diri akademik mahasiswa pascasarjana. Scholaria: Jurnal Pendidikan dan Kebudayaan, 7(3), 226-233, 2017, DOI: 10.24246/j.scholaria.2017.v7.i3. p226-233.

Valentine, V. J., DuBois, D. L., \& Cooper, H. (2004). The relation between self-beliefs and academic achievement: A meta-analytic review. Educational Psychologist, 39, 111-133.

Villar, C. P. D. (2010). Beginning Filipino students' attributions about oral communication anxiety. Journal Media and Communication Studies, 2(7), 159-169.

Wigfield, A., \& Karpathian, M. (2009). Who am I and what can I do? Children's self-concepts and motivation in achievement situations. Educational Psychologist, 26, 233-261, 1991.

Yahaya, A., \& Ramli, J. (2009). The relationship between self-concept and communication skills towards academic achievement among secondary school students in Johor Bahru. International Journal of Psychological Studies, 1(2), 25-34.

Yaikhong, K., \& Usaha, S. (2012). A measure of EFL public speaking class anxiety: Scale development and preliminary validation and realiability. English Language Teaching, 5(12), 23-35.

Zhiping, D., \& Paramasivam, S. (2013). Anxiety of speaking English in class among international students in a Malaysian University. International Journal of Education and Research, 1(11), 1-16. 